\title{
CONVENTIONAL SURGERY V/S INTERVENTIONAL MANAGEMENT OF PERI- PANCREATIC COLLECTIONS RELATED TO ACUTE PANCREATITIS
}

\author{
Talha Yasin, Nasir Mehmud Wattoo, Qasim Butt, Kamran Safdar, Saad Rao \\ Pak Emirates Military Hospital/National University of Medical Sciences (NUMS) Rawalpindi Pakistan
}

\begin{abstract}
Objective: To determine the difference in outcomes of conventional surgery v/s. interventional methods for peripancreatic collections after acute pancreatitis at Pak Emirates Military Hospital and Combined Military Hospital Rawalpindi.

Study Design: Prospective comparative study.

Place and Duration of Study: Pak Emirates Military Hospital and Combined Military Hospital Rawalpindi, from Apr 2018 to Mar 2019.

Methodology: A prospective study was conducted on 100 patients who underwent either surgical or intervenetional management of peri-pancreatic collections after an episode of acute pancreatitis. Detailed assessments of positive outcomes and all side effects were done immediately post-procedure, at 48 hours, at the time of discharge and two weeks after procedure on all the participants.

Results: Out of 100 patients included in the final analysis 78 were male and 22 were female. Mean age of patients in our study who underwent either surgery or intervention for peri-pancreatic collection was $42.41 \pm 3.521$ years. Mean duration of hospital stay after the surgery was $6.93 \pm 4.662$ days. Using binary logistic regression we found no statistically significant difference between both approaches in terms of positive outcomes or therapeutic use but presence of infection and readmission in hospital had a strong relationship with conventional surgery ( $p$-value $<0.05)$.

Conclusion: No statistically significant difference in therapeutic use was observed, however, complication rate, especially infections and readmission was statistically significantly higher among the patients undergoing conventional surgery as compared to interventional management.
\end{abstract}

Keywords: Acute pancreatitis, Endoscopic intervention, Peri-pancreatic collection, Surgical method.

This is an Open Access article distributed under the terms of the Creative Commons Attribution License (http://creativecommons.org/licenses/by/4.0), which permits unrestricted use, distribution, and reproduction in any medium, provided the original work is properly cited.

\section{INTRODUCTION}

Acute pancreatitis is a common clinical condition which general surgeons all around the world encounter in their day-to-day clinical practice $^{1}$. In addition to the causative factors related to the patient, iatrogenic factors also play a considerable role in the precipitation of serious complications associated with this pathology ${ }^{2}$. Incidence of this problem is almost equal in all parts of the world including the developed as well as the developing countries like Pakistan ${ }^{3,4}$. Most of the times, acute pancreatitis resolves with conservative management without any serious outcomes, but occasionally it can lead to or even present with serious life threatening complications.

Correspondence: Dr Talha Yasin, Army Liver Transplant Unit, Pak Emirates Military Hospital, Rawalpindi Pakistan

Received: 31 May 2019; revised received: 20 Aug 2019; accepted: 26 Aug 2019
Some of them include pancreatic necrosis, peripancreatic fluid collection, pancreatic pseudocyst formation, pancreatic duct disruption, adjacent vascular involvement and torrential bleed, electrolyte imbalance, sepsis and multi-organ failure ${ }^{5,6}$. A surgeon should have thorough knowledge of the entire spectrum of this disease and upto-date management of all the complications related to it.

Various methods have been analyzed and adopted over time to manage the collections around the pancreas after an episode of acute pancreatitis. Conventional surgery was treatment of choice in the past but minimally invasive endoscopic procedures have emerged as a preferred approach in the last few years for management of hepatobiliary and the pancreatic pathologies 7,8 . Surgical advancements have also led to an increa- 
sing role of laparoscopic surgery as an adjunct to interventional gastroenterology in the management of hepato-biliary pathology. It has shown a clear advantage over the conventional open method $^{9}$. It has been demonstrated in the past that the conventional surgical methods for removal of peri-pancreatic fluid have good therapeutic outcomes but complications are much more common and severe compared to the less invasive methods used for this purpose ${ }^{10}$. Another large review article published similar findings that aggressive conservative management followed by endoscopic procedure (if required) reduces the chances of open surgery and limits the complications for these seriously ill patients ${ }^{11}$. A large systematic review on this subject has revealed endoscopic management followed by stenting to be superior to the conventional surgery in terms of the number and nature of post-procedural complications. Emphasis has been laid on multidisciplinary approach involving surgeons, interventional radiologists, gastroenterologists and critical care specialists ${ }^{12}$.

Previous studies have clearly demonstrated a better safety profile of endoscopic procedures for peri-pancreatic fluid collections but many complications have been seen to arise especially due to poor interventional or endoscopic skills in the management of biliary pathologies or due to unavailability of resources, facilities and skilled staff. Perforation, bleeding and secondary infections are some of the commonly occurring complications in the patients undergoing endoscopic procedure for the drainage of peri-pancreatic fluid collections ${ }^{13,14}$.

Working in western countries allows the treating physicians to discuss treatment options with the patients in detail along with the outcome of the procedures. But in the developing countries, cost and availability of different treatment modalities and skilled staff has been a limiting factor in provision of adequate services resulting in quicker and better outcomes, especially in the military settings, where early recovery and reducing the number of days with disability are a priority. We, therefore, planned this study to gen- erate a baseline data for the surgeons as well as future researchers regarding the comparison of surgical and interventional management of the peri-pancreatic collections among the patients suffering from acute pancreatitis presenting at a tertiary care military hospital of Pakistan.

\section{METHODOLOGY}

This prospective comparative study was conducted at the surgery and gastroenterology departments of Pak Emirates Military Hospital and Combined Military Hospital Rawalpindi from April 2018 to March 2019. Sample size was calculated by WHO sample size calculator with population prevalence proportion of $95 \%$ and 60 patients were included in intervention group while 40 were included in surgery group ${ }^{10}$. Non probability consecutive sampling technique was used to gather the sample. All patients between the ages of 18 and 60 years, who underwent either surgical or endoscopic procedures for fluid collections around the pancreas after acute pancreatitis were included in the study after the ethics approval from the ethical review board committee and written informed consent from participants. Patients referred from other military, public and private hospitals who underwent any surgical or interv-entional procedure for peripancreatic collections at our hospital were also included in the analysis in addition to the patients of above said hospitals. Exclusion criteria was patients under 18 years of age or those with any co-morbidity including patients with a known gallbladder carcinoma or any other solid organ or hematological malignancy. Patients with peri-pancreatic collections secondary to reasons other than acute pancreatitis and those undergoing redo surgeries or procedure were also excluded from the analysis. A special proforma was designed for this study including the socioeconomic demographic profile and all the possible complications of the procedures. Gastroenterology department was taken on board and involved in the planning of study from the start.

Routine analgesia and antibiotic cover was given to each patient as per the hospital protocol. 
Detailed assessment of all the outcomes was done immediately post-procedure, at 48 hours, at the time of discharge and two weeks after the date of procedure on all the participants. Interventional methods include placement of an external drainage catheter into the pseudocyst using real-time imaging guidance, usually computed tomography (CT) or ultrasound (US) along with fluoroscopy while surgical interventions include either open or laparoscopic approach in which an anastomosis is created between the lumen of the cyst cavity and the stomach or small bowel using suturing or stapling devices 7,8 .

Infection, perforation, bleeding, and readmission due to primary procedure were the most common short term complications noted among the study cohort during the study period. Positive outcomes included successful resolution of the collection and discharge. Mean hospital stay was calculated for all study participants.

All statistical analysis was performed by using the SPSS-24. Frequency and percentages for categorical variables included in the study were calculated. Mean and standard deviation quantitative variables was also calculated for the study participants. Variableswere compared in both the groups by using the chi-square test and binary logistic regression.

\section{RESULTS}

A total of 108 patients were initially approached for enrolment in the study. Two were diagnosed to have complications secondary to pathology other than acute pancreatitis while four were undergoing redo surgeries. Two subjects did not consent to be a part of the study. Out of 100 patients included in the final analysis $78(78 \%)$ were male and $22(22 \%)$ were female. Mean age of patients undergoing any kind of intervention conventional or otherwise was $42.41 \pm 3.521$ years. Mean duration of hospital stay after the conventional surgery was $6.93 \pm 4.662$ days. Other characteristics of the patients have been summarized in the table-I.

With binary logistic regression we found that there was no difference in the positive outcomes or therapeutic use of both the procedures but presence of infections and readmission to the hos-

Table-I: Characteristics of the study groups and application of chi-square test.

\begin{tabular}{|c|c|c|c|}
\hline $\begin{array}{l}\text { Socio } \\
\text { Demographic } \\
\text { Factors }\end{array}$ & $\begin{array}{c}\text { Intervention } \\
\text { Group } \\
\mathbf{n}(\%)\end{array}$ & $\begin{array}{c}\text { Surgery } \\
\text { Group } \\
\text { n (\%) }\end{array}$ & $\begin{array}{c}p- \\
\text { value }\end{array}$ \\
\hline \multicolumn{4}{|l|}{ Age } \\
\hline $\begin{array}{l}<30 \text { year } \\
30-65\end{array}$ & $\begin{array}{l}24(40) \\
36(60)\end{array}$ & $\begin{array}{l}22(55) \\
18(45)\end{array}$ & 0.140 \\
\hline \multicolumn{4}{|l|}{ Gender } \\
\hline $\begin{array}{l}\text { Male } \\
\text { Female }\end{array}$ & $\begin{array}{l}44(73.3) \\
16(26.7)\end{array}$ & $\begin{array}{l}34(85) \\
06(15)\end{array}$ & 0.160 \\
\hline \multicolumn{4}{|c|}{ Presence of Infection } \\
\hline $\begin{array}{l}\text { No } \\
\text { Yes }\end{array}$ & $\begin{array}{l}51(85) \\
09(15)\end{array}$ & $\begin{array}{l}32(80) \\
08(20)\end{array}$ & $<0.001$ \\
\hline \multicolumn{4}{|l|}{ Perforation } \\
\hline $\begin{array}{l}\text { No } \\
\text { Yes }\end{array}$ & $\begin{array}{l}51(85) \\
09(15)\end{array}$ & $\begin{array}{l}22(55) \\
08(45)\end{array}$ & 0.182 \\
\hline \multicolumn{4}{|l|}{ Bleeding } \\
\hline $\begin{array}{l}\text { No } \\
\text { Yes }\end{array}$ & $\begin{array}{l}53(88.3) \\
07(11.7)\end{array}$ & $\begin{array}{l}34(85) \\
06(15)\end{array}$ & 0.629 \\
\hline \multicolumn{4}{|l|}{ Readmission } \\
\hline $\begin{array}{l}\text { No } \\
\text { Yes }\end{array}$ & $\begin{array}{c}58(96.6) \\
02(3.4)\end{array}$ & $\begin{array}{l}30(75) \\
10(25)\end{array}$ & 0.001 \\
\hline \multicolumn{4}{|c|}{ Positive outcome } \\
\hline $\begin{array}{l}\text { No } \\
\text { Yes }\end{array}$ & $\begin{array}{c}49(81.6) \\
11(8.4)\end{array}$ & $\begin{array}{l}31(77.5) \\
09(22.5)\end{array}$ & 0.611 \\
\hline
\end{tabular}

Table-II: The correlated factors relating to the type of modality used among the patients suffering from peri-pancreatic accumulation after acute pancreatitis: the binary logistic regression analysis.

\begin{tabular}{l|c|c|c|c}
\hline & $\begin{array}{c}p \text { - } \\
\text { value }\end{array}$ & $\begin{array}{l}\text { Odds } \\
\text { Ratio }\end{array}$ & \multicolumn{2}{|c}{$\begin{array}{c}\text { Confidence } \\
\text { Interval }\end{array}$} \\
\cline { 4 - 5 } & Lower & Upper \\
\hline $\begin{array}{l}\text { Age (ref. is 30 } \\
\text { years or less) }\end{array}$ & 0.360 & 0.647 & 0.255 & 1.643 \\
\hline $\begin{array}{l}\text { Readmission } \\
\text { (ref. is no } \\
\text { readmission) }\end{array}$ & 0.045 & 5.929 & 1.020 & 34.447 \\
\hline $\begin{array}{l}\text { Gender (ref. is } \\
\text { male) }\end{array}$ & 0.128 & 0.372 & 0.104 & 1.328 \\
\hline $\begin{array}{l}\text { Perforation (ref. } \\
\text { is no } \\
\text { perforation) }\end{array}$ & 0.778 & 1.218 & 0.310 & 4.793 \\
\hline $\begin{array}{l}\text { Bleeding (ref. is } \\
\text { no bleeding) }\end{array}$ & 0.733 & 1.302 & 0.286 & 5.927 \\
\hline $\begin{array}{l}\text { Infection (ref. is } \\
\text { no infection) }\end{array}$ & 0.002 & 12.151 & 2.543 & 58.058 \\
\hline $\begin{array}{l}\text { Positive } \\
\text { outcome (ref. is } \\
\text { no positive } \\
\text { outcome) }\end{array}$ & 0.449 & 0.573 & 0.135 & 2.422 \\
\hline
\end{tabular}


pital had a stronger relationship to conventional surgical procedures, highlighting significant difference in the complication rate of the two modalities (table-II).

\section{DISCUSSION}

Last two decades have seen exponential advancements in the interventional and minimally invasive fields, thereby, lessening the overall operative burden of almost all surgical specialties ${ }^{15}$. These advancements have also helped reduce the severity and complexity of complications associated with the conventional surgical methods. The rate of conventional hepato-biliary and pancreatic surgeries have gone down after a revolution in endoscopic gastroenterological interventions ${ }^{6}$. These new interventions have their own merits and demerits and are not complication free, though, the number and complexity of complications is much lower when compared to conventional approaches. These interventions also demand the availability of highly sophisticated and expensive equipment with staff requiring extensive targeted training to develop and hone required skills, which usually is a problem in developing countries like Pakistan. Ours is a tertiary care military hospital which has a well-equipped surgical department, gastroenterology unit and interventional radiology unit which offer all modern treatments at a reasonable costs. We, therefore, planned this study to see the difference in outcomes between patients undergoing either conventional surgical or interventional, minimally invasive approaches for peri-pancreatic fluid collection after acute pancreatitis.

100 patients participated in the study. There was no difference in the therapeutic efficacy of either approach. This highlights the fact that conventional procedures were as good as endoscopic or minimally invasive approaches in resolving the primary issue of peri-pancreatic collections except that the rate and complexity of complications and duration of hospital stay was slightly higher in the conventional arm of the study, thereby, acting as the deciding factor for the latest tilt towards minimally invasive and endoscopic approaches. Similar results have also been reported on multiple occasions in the existing literature by Freeman et al, and Karakyaki et al10,16. Freeman et al, concluded that morbidity rate may reach up to $95 \%$ during these procedures. Though randomized control trials are still lacking on this subject due to ethical issues, patient preferences and availability of equipment and expertise; it has been clear that both procedures have been equally good in achieving the primary outcome.

Being from military settings our focus is on early recovery and minimal number of disability days post-procedure, therefore, we intend to balance the provision of latest interventional techniques with cost-effectiveness of the same to find a perfect solution for the military personals without compromising on the quality of treatment and outcomes.

Infection rate was statistically different in both the groups. Patient undergoing conventional surgery were at an increased risk of developing infections as compared to the patients undergoing endoscopic intervention in our target population. Similar results have been reported in systematic reviews in the past as well by Navadagi et al, in 2015 and Bendersky et al, in 201617,18. Surgical wound itself which is a part of the open surgical approach and absent in interventional management is a potential ground for infection. Therefore, open surgical intervention may seem cost effective initially, but in the long run, it has a potential to tilt the scales in the opposite direction due to a higher risk of wound infections, prolonged use of antibiotics, longer hospital stay, higher rate of re-admission, increased disability days and gross decrease in productivity, all of which are extremely important factors when considering treatment options in military personals. Increased rate of infection, which has already been documented in our study may be one of the causes of higher re-admission rate. Both chisquare and logistic regression analysis proved this association in our study. Tertiary care hospitals receive patients from far flung areas as well, so readmission due to complications of the 
primary procedure poses a huge burden on the health care system. Military settings specifically discourage such practices which imply greater risk of complications and re-admissions in favor of the methods which have shown to decrease these outcomes. Findings of multiple international systematic reviews and studies also favor the findings of our study where readmission rates have been found more in patients undergoing conventional surgeries as compared to endoscopic interventional managements ${ }^{11,12}$. Swartz et al, and tyberg et al, showed significant association in this regard $(p \text {-value }<0.05)^{11,12}$.

There was no difference in the incidence of perforation or bleeding among the two groups on any statistical test applied and these specific complications have been studied in both group of patients in the past as well by Nabi et al, and Saumoy et al ${ }^{13,14}$. Similar results were obtained in case series published by Malik et al. Which showed that laparoscopic procedure was a safe open surgical method for peri pancreatic collections and average hospital stay was $4.1 \pm 2.3$ days $^{19}$. Therefore all these risks and benefits of all available procedures should be discussed in detail with the patient to gain an informed consent for further management.

One of the major limitations in generalizing the results of this study has been the study design. A randomized control trial would have served the purpose better but ethical problems, cost issues for the private patients and availability of trained professionals all the time were the hurdles for us in developing and conducting a randomized control trial. Moreover, the difference in open and laparoscopic surgical methods have not been studied yet, which would have resulted in a bias in the outcomes associated with the surgical group. Sample was mainly drawn from military population as ours is a tertiary care military hospital made primarily for serving and retired soldiers, therefore, generalizing the results to a larger more diverse population sample in terms of socio-economic statuses, accessibility to tertiary facilities, nature, intensity and complexity of disease would skew the results.

\section{CONCLUSION}

No difference in therapeutic use was observed, however, complication rate especially infections and readmission was significantly high among the patients undergoing surgical management as compared to interventional management. Endoscopic intervention emerged as a safer method for the management of peri-pancreatic collection among the patients suffering from acute pancreatitis as compared to the conventional surgical method.

\section{CONFLICT OF INTEREST}

This study has no conflict of interest to be declared by any author..

\section{REFERNCES}

1. Shah AP, Mourad MM, Bramhall SR. Acute pancreatitis: current perspectives on diagnosis and management. J Inflamm Res 2018; 11(1): 77-85.

2. Jung MK, Jang $\mathrm{YJ}$, Cho CM. Iatrogenic pancreatitis in patients with IPMN after ERCP: incidence and predictive signs. Abdom Imag 2014; 39(5): 949-54.

3. Krishna SG, Kamboj AK, Hart PA, Hinton A, Conwell DL. The Changing Epidemiology of Acute Pancreatitis Hospitalizations: A Decade of Trends and the Impact of Chronic Pancreatitis. Panc 2017; 46(4): 482-88.

4. Roberts SE, Akbari A, Thorne K, Atkinson M, Evans PA. The incidence of acute pancreatitis: impact of social deprivation, alcohol consumption, seasonal and demographic factors. Aliment Pharmacol Ther 2013; 38(5): 539-48.

5. Bruno MJ, Dutch Pancreatitis Study Group. Improving the Outcome of Acute Pancreatitis. Dig Dis 2016; 34(5): 540-45.

6. Afghani E, Pandol SJ, Shimosegawa T, Sutton R, Bechien U, Vege SS, et al. Acute Pancreatitis-Progress and Challenges: A Report on an International Symposium. Pancreas 2015; 44(8): 1195-10.

7. Lichtenstein GR. Advances in the Field of Gastroenterology and Hepatology. Gastroenterol Hepatol (NY) 2016; 12(4): 209-12.

8. Nabi Z, Reddy DN. Advanced Therapeutic gastrointestinal endoscopy in children-today and tomorrow. Clin Endosc 2017; 51(2): 142-49.

9. Justin V, Fingerhut A, Khatkov I, Uranues S. Laparoscopic pancreatic resection-a review. Transl Gastroenterol Hepatol. 2016; $1(1): 36-42$.

10. Freeman ML, Werner J, van Santvoort HC, Baron TH, Besselink MG, Windsor JA et al. Interventions for necrotizing pancreatitis: summary of a multidisciplinary consensus conference. Pancreas. 2012;41(8):1176-94.

11. Swartz DK, Obando J. Endoscopic management of peri-pancreatic collections. Gastroenterol Res Pract 2012; 2012(1): 906381-85.

12. Tyberg A, Karia K, Gabr M, Desai A, Doshi R, Gaidhane M, et al. Management of pancreatic fluid collections: A comprehensive review of the literature. World J Gastroenterol 2016; 22(7): 22562270.

13. Nabi Z, Basha J, Reddy DN. Endoscopic management of pancreatic fluid collections-revisited. World J Gastroenterol 2017; 23(15): 2660-72. 
14. Saumoy M, Kahaleh M. Safety and complications of Interventional endoscopic ultrasound. Clin Endosc 2017; 51(3): 235-38.

15. Yip HC, Teoh AYB. Endoscopic management of peri-pancreatic fluid collections. Gut Liver 2017; 11(5): 604-11.

16. Karakayali FY. Surgical and interventional management of complications caused by acute pancreatitis. World J Gastroenterol 2014; 20(37): 13412-23.
17. Bendersky VA, Mallipeddi MK. Necroti-zing pancreatitis: challenges and solutions. Clin Exp Gastroen-terol 2016; 9(1): 345-50.

18. Navadgi S, Pandanaboyana S, Windsor JA. Surgery for Acute Pancreatitis. Ind J Surg 2015; 77(5): 446-52.

19. Malik AA, Isnain HG, Khan A, Toor AA, Nawaz A, Mansoor R, et al. Laparoscopic cystgastrostomy: A Pakistani perspective. J Pak Med Assoc 2015; 65(5): 565-68. 